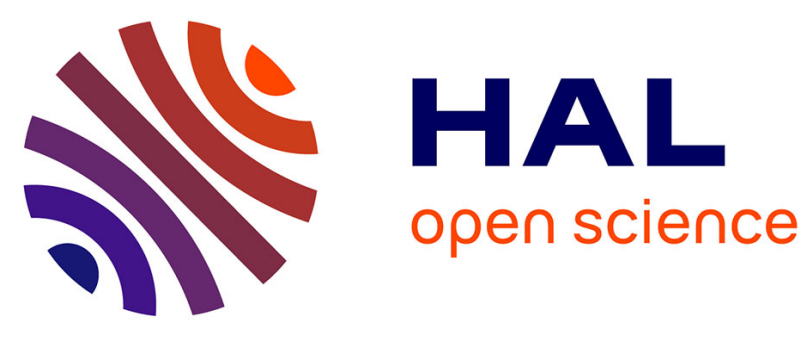

\title{
Video laryngoscopy versus direct laryngoscopy for orotracheal intubation in the intensive care unit: a systematic review and meta-analysis
}

Audrey de Jong, Nicolas Molinari, Matthieu Conseil, Yannaël Coisel, Yvan Pouzeratte, Fouad Belafia, Boris Jung, Gerald Chanques, Samir Jaber

\section{To cite this version:}

Audrey de Jong, Nicolas Molinari, Matthieu Conseil, Yannaël Coisel, Yvan Pouzeratte, et al.. Video laryngoscopy versus direct laryngoscopy for orotracheal intubation in the intensive care unit: a systematic review and meta-analysis. Intensive Care Medicine, 2014, 10.1007/s00134-014-3236-5 . hal02549897

\section{HAL Id: hal-02549897 \\ https://hal.umontpellier.fr/hal-02549897}

Submitted on 21 Apr 2020

HAL is a multi-disciplinary open access archive for the deposit and dissemination of scientific research documents, whether they are published or not. The documents may come from teaching and research institutions in France or abroad, or from public or private research centers.
L'archive ouverte pluridisciplinaire HAL, est destinée au dépôt et à la diffusion de documents scientifiques de niveau recherche, publiés ou non, émanant des établissements d'enseignement et de recherche français ou étrangers, des laboratoires publics ou privés. 
Audrey De Jong

Nicolas Molinari

Matthieu Conseil

Yannael Coisel

Yvan Pouzeratte

Fouad Belafia

Boris Jung

Gérald Chanques

Samir Jaber

\section{Video laryngoscopy versus direct laryngoscopy for orotracheal intubation in the intensive care unit: a systematic review and meta-analysis}

Take-home message: Video laryngoscopy for orotracheal intubation in the ICU could be useful in airway management of ICU patients. It helps to reduce difficult intubation, esophageal intubation, and Cormack 3/4 grades and increases firstattempt success.

\author{
A. De Jong - M. Conseil · \\ Y. Coisel · Y. Pouzeratte $\cdot$ F. Belafia \\ B. Jung - G. Chanques - S. Jaber ( \\ Intensive Care Unit, Anesthesia and Critical \\ Care Department, Saint Eloi Teaching \\ Hospital, University Montpellier 1, \\ 80 Avenue Augustin Fliche, \\ 34295 Montpellier Cedex 5, France \\ e-mail: s-jaber@chu-montpellier.fr \\ Tel.: +33-4-67337271 \\ Fax: +33-4-67337448 \\ N. Molinari \\ Department of Statistics, University of \\ Montpellier Lapeyronie Hospital, UMR 729 \\ MISTEA, Montpellier, France
}

\author{
N. Molinari - B. Jung · \\ G. Chanques $\cdot$ S. Jaber \\ Unité U1046 de l'Institut National de la \\ Santé et de la Recherche Médicale \\ (INSERM), University of Montpellier, \\ Montpellier, France
}

Abstract Purpose: Single studies of video laryngoscopy (VL) use for airway management in intensive care unit (ICU) patients have produced controversial findings. The aim of this study was to critically review the literature to investigate whether VL reduces difficult orotracheal intubation (OTI) rate, first-attempt success, and complications related to intubation in ICU patients, compared to standard therapy, defined as direct laryngoscopy (DL). Methods: We performed a systematic review and meta-analysis of randomized controlled trials, as well as prospective and retrospective observational studies, by searching PubMed, EMBASE and bibliographies of articles retrieved. We screened for relevant studies that enrolled adults in whom the trachea was intubated in the ICU and compared VL to DL. We included studies reporting at least one clinical outcome of interest to perform a meta-analysis. We generated pooled odd ratios (OR) across studies. The primary outcome measure was difficult OTI. The secondary outcomes were first-attempt success, Cormack 3/4 grades, and complications related to intubation (severe hypoxemia, severe cardiovascular collapse, airway injury, esophageal intubation). Results: Nine trials with a total of 2,133 participants (1,067 in DL and 1,066 in VL) were included in the current analysis. Compared to DL, VL reduced the risk of difficult OTI [OR $0.29(95 \%$ confidence interval (CI) $0.20-0.44$, $p<0.001)$ ], Cormack 3/4 grades [OR 0.26 (95\% CI 0.17-0.41,

$p<0.001)]$, and esophageal intubation [0.14 (95\% CI 0.02-0.81, $p=0.03)]$ and increased the firstattempt success [OR 2.07 (95\% CI $1.35-3.16, p<0.001)]$. No statistically significant difference was found for severe hypoxemia, severe cardiovascular collapse or airway injury.

Conclusions: These results suggest that VL could be useful in airway management of ICU patients.

Keywords Intubation .

Video-laryngoscope .

Video laryngoscopy · Macintosh · Critical care - Intensive care .

Complications 


\section{Introduction}

Airway management in intensive care unit (ICU) patients is challenging [1]. Difficult orotracheal intubation (OTI) and complications related to OTI are higher than in operative rooms [2-4] and difficult OTI is associated with life-threatening complications $[1,4]$. New video laryngoscopy (VL) devices are proposed to improve airway management [5] and to reduce difficult OTI incidence in operative rooms [6]. Video laryngoscopes are devices that contain a miniaturized camera towards the tip of the blades to indirectly visualize the glottis. By improving glottis visualization, the VL could help to decrease difficult intubation and reduce complications related to intubation in the ICU. However, its use in the ICU is more recent [7, 8] than in operative rooms and its effectiveness in increasing first-attempt success and reducing difficult OTI or complications related to intubation remains debated [9]. Single studies of VL in the airway management in ICU patients have produced controversial findings, improving [7] or worsening [10] the airway management (i.e., firstattempt success, difficult intubation, glottis visualization, or complications related to intubation). Given this controversy, our goal was to perform a systematic review and meta-analysis of randomized and non-randomized studies comparing VL to direct laryngoscopy (DL) regarding difficult OTI, successful first-attempt of OTI, Cormack 3/4 grades, and complications related to intubation.

We chose to focus on the critical care setting, excluding emergency and anesthesia settings. In addition, we explored the heterogeneity of these outcomes based on the type of ICU and according to the device used.

\section{Methods}

This article reports our meta-analysis and systematic review of studies of VL compared to DL in accordance with the preferred reporting items for systematic reviews and meta-analyses (PRISMA) statement [11].

\section{Search strategy}

We performed a computerized search of MEDLINE (1966 to 31 November 2013), EMBASE (1977 to 31 November 2013), and the Cochrane Center Register of Controlled Trials (CENTRAL) (1943 to 31 November 2013) for studies comparing VL to DL regarding the difficulty of OTI, glottis view, successful first-attempt OTI, and complications of OTI in the ICU. We included non-English-language publications. We searched abstracts of selected conferences from 2010 to 2013, including those of the American Society of Anesthesiologists, the Canadian Anesthesiologists' Society, the
International Anesthesia Research Society, the American Thoracic Society, the European Society of Anesthesiology, the European Society of Intensive Care Medicine, the Société Française d'Anesthésie Réanimation, and the Société de Réanimation de Langue Française.

For the bibliographic review, keywords ("video", "GlideScope", "Airtraq", "X-Lite", "Storz", "McGrath", "Pentax"), medical subject headings ("laryngoscopes", "videotape recording", "intubation", "intensive care unit", and "critical care"), and Emtree terms ("laryngoscope", "video-laryngoscope", "videolaryngoscopy", "video recording", and "respiratory tract intubation") were used in our Boolean search strategy. References in the retrieved articles were also examined for relevant publications. We identified and deleted any duplicate papers. All potentially eligible papers were retrieved in full.

Selection criteria and outcome measures

We screened for relevant studies that enrolled adults in whom the trachea had been orally intubated in the ICU (excluding emergency setting and operative rooms) and compared VL to DL.

Then we made a quantitative synthesis performing a meta-analysis and systematic review. For this purpose, we selected the following study designs: randomized controlled trials (RCTs), prospective observational studies (before and after treatment), and retrospective observational studies.

The primary evaluation criterion was the incidence of difficult OTI, defined strictly as more than two attempts of intubation [12]. The other endpoints of firstattempt success, glottis view (Cormack 3/4 grades), and complications related to OTI [severe hypoxemia (defined as saturation less than $80 \%$ ) [1-3], severe cardiovascular collapse (defined as systolic blood pressure less than $70 \mathrm{mmHg}$ and/or requiring introduction of vasoactive support) [1-3], airway injury (tissue injury, bleeding, glottis swelling), esophageal intubation] were analyzed. We included studies reporting at least one clinical outcome of interest to perform a meta-analysis.

\section{Data collection and analysis}

First, two authors (A.D.J. and B.J.) independently screened the retrieved studies by title and then by abstract for exclusion. They assessed the full text of the possibly relevant studies for inclusion and exclusion criteria. Disagreement was resolved by discussion and arbitrated if necessary by a third author (S.J.). Data were then added to an Excel database, specifically designed for this review and analyzed in RevMan 5.2 software. 


\section{Statistical analysis}

Data were extracted as they were reported in the original paper or on the basis of the authors' answers to our queries. Included studies were appraised for their risk of bias by two independent authors (A.D.J., N.M.) using the Cochrane Collaboration tool [13] for assessing risk of bias in RCTs and the Newcastle-Ottawa scale [14] for assessing risk of bias in observational studies. Data synthesis was deemed appropriate if clinical heterogeneity and methodological heterogeneity were negligible [15]. Clinical heterogeneity was assessed by judgment based on exploration of the characteristics of the included studies table. We used fixed or random effects models, depending on statistical heterogeneity between studies, to calculate summary estimates. We used odds ratio (OR) as the summary measure for dichotomous outcomes. Statistical heterogeneity was quantified by the Q-Cochrane heterogeneity test $[Q$ statistic with degree of freedom $(d f)]$ and the $I^{2}$ statistic [13]. In case of heterogeneity, a random effect model was performed and the cause of heterogeneity was then explored in sensitivity analyses. A priori, we decided to perform sensitivity analyses excluding trauma studies, observational studies, non-Glidescope ${ }^{\circledR}$ studies and study with high risk of bias. All tests were two sided and $p$ values less than 0.05 were considered statistically significant. A funnel plot (plot of treatment effect against trial precision) was also created to determine the presence of publication bias and other possible biases (English language, citation, and multiple publication), true heterogeneity, data irregularities, and choice of effect measure in the meta-analysis. In the presence of bias that usually leads to an overestimate of the treatment effect, the funnel plot is skewed and asymmetrical.

\section{Results}

Study selection

We identified 317 articles using the search strategy. We excluded 156 citations because of duplications and 152 citations on the initial abstract screen because inclusion criteria were not met. After examination of the full text of the selected papers, we included nine studies (observational studies and RCTs) for the meta-analysis. Figure 1 shows the study selection flow chart.

\section{Study description}

The nine studies involved a total of 2,133 participants (157 in RCTs and 1,976 in observational studies) from four countries (USA $n=6$, Canada $n=1$, Australia $n=1$, France $n=1)$. Then, 1,067 participants were analyzed in the DL group and 1,066 in the VL group. Table 1 presents the characteristics of the studies included in the systematic review.

\section{Randomized controlled studies}

Three studies (Table 1) were designed as prospective, open studies, reported in English, in critically ill patients, from 2012 to 2013 [10, 16, 17].

\section{Observational studies}

Three studies were before-after studies [8, 18, 19], one was a historico-prospective cohort [7], one was retrospective [20], and one was prospective non-randomized [21] (Table 1).

\section{Risk of bias and quality assessment}

All RCTs were identified with low to moderate risk of bias according to the Cochrane Collaboration's tool. Observational studies had low to moderate risk of bias, except for one study [21], that had high risk of bias, according to the Newcastle-Ottawa scale. The "firstattempt success" outcome was the only one reported in all studies. Difficult OTI, Cormack 3/4 grades, severe hypoxemia, severe cardiovascular collapse, airway injuries, and esophageal intubation were respectively reported in 7 , 5, 6, 5, 3, and 7 studies, respectively (Fig. 1).

\section{Outcomes \\ Difficult OTI}

Seven studies presented results for the "difficult OTI " outcome (Fig. 2) [7, 8, 16-18, 20, 21]. The pooled OR across all studies was 0.29 [95\% confidence Interval (CI) $0.20-0.44, p<0.001$ ], indicating less difficult OTI using VL when compared to DL. There was no heterogeneity for this outcome. There was no evidence of publication bias on the funnel plot (Fig. E1 in Electronic Supplementary Material (ESM)).

\section{First attempt success}

All nine studies presented results for the "first-attempt success" outcome (Fig. 3) [7, 8, 10, 16-21]. The pooled OR across all studies was 2.07 (95\% CI 1.35-3.16, $p<0.001$ ), indicating a higher first-attempt success rate using VL when compared to DL. There was significant between-study heterogeneity for this outcome $(Q=24.7$, $d f=8, p=0.002$ ), with a corresponding $I^{2}$ statistic of $68 \%$. There was no evidence of publication bias on the funnel plot (Fig. E2 in ESM). 


\section{Cormack 3/4 grades}

Five studies presented results for the "Cormack 3/4 grades" outcome (Fig. 4) [8, 16-18, 21]. The pooled OR across all studies was 0.26 (95\% CI $0.17-0.41, p<0.001)$, indicating better glottis visualization using VL when compared to DL. There was no heterogeneity for this outcome. There was no evidence of publication bias on the funnel plot (Fig. E3 in ESM).

\section{Complications related to intubation}

\section{Severe hypoxemia}

Six studies presented results for the "saturation less than $80 \% "$ outcome [7, 8, 10, 17, 18, 20]. The pooled OR across all studies was $1.24(95 \%$ CI $0.70-2.19, p=0.46$, Fig. 5a), indicating no difference using VL when compared to DL. However, there was significant betweenstudy heterogeneity in these results $(Q=11.25, d f=5$, $p=0.05)$, with an $I^{2}$ statistic of $56 \%$.
Fig. 1 Flow chart of studies selected for the meta-analysis

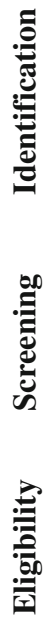

297 of records identified through database searching
20 of additional records identified through other sources

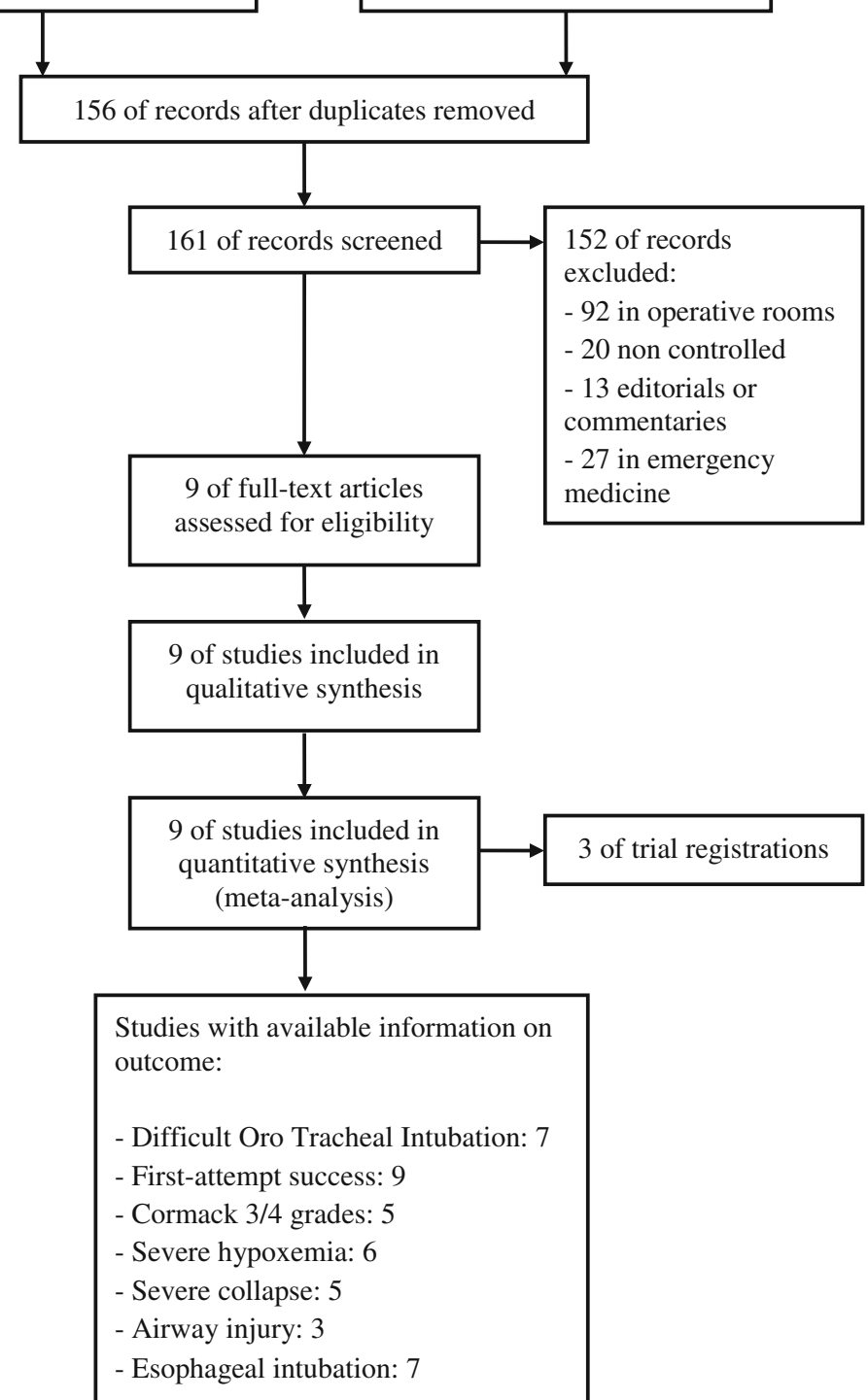




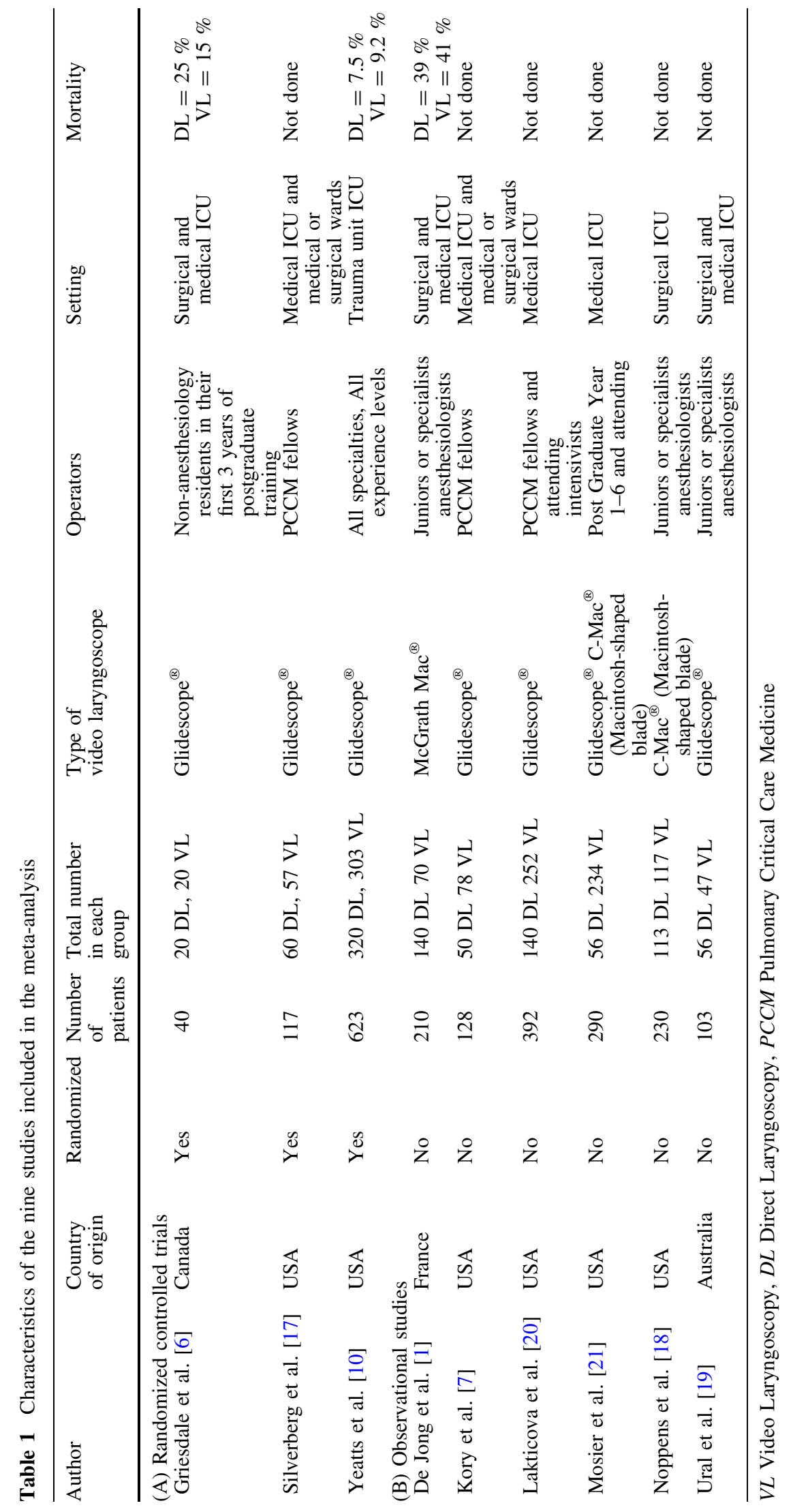




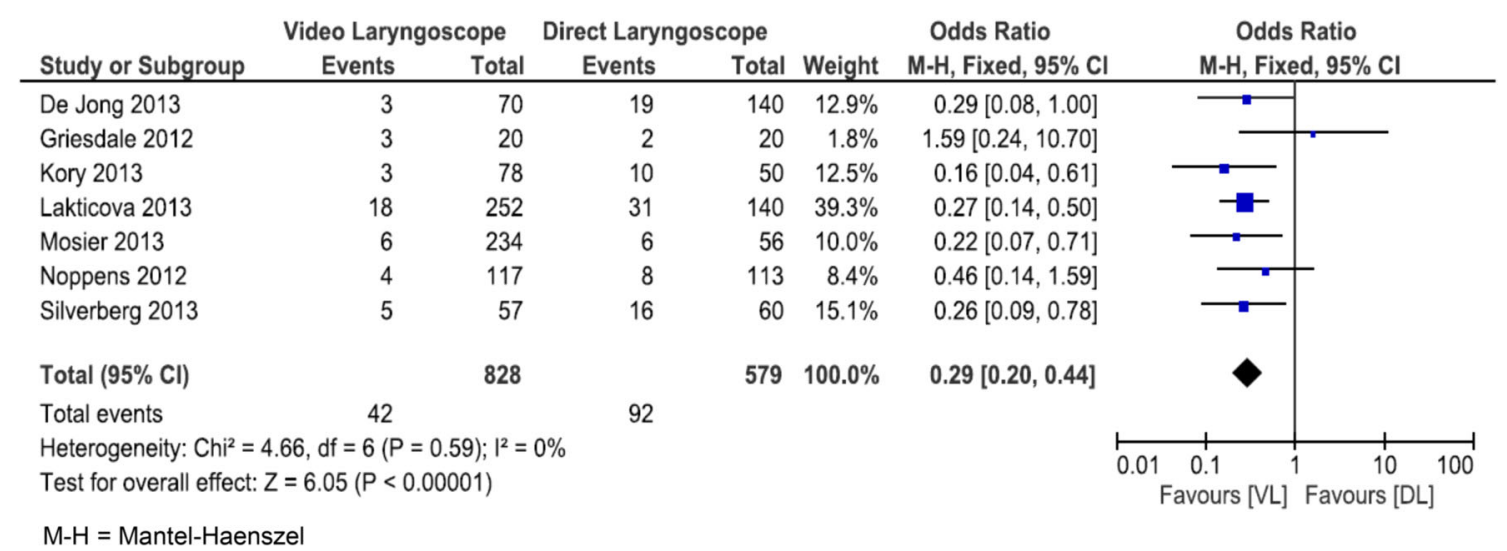

Fig. 2 Forest plot of difficult intubation

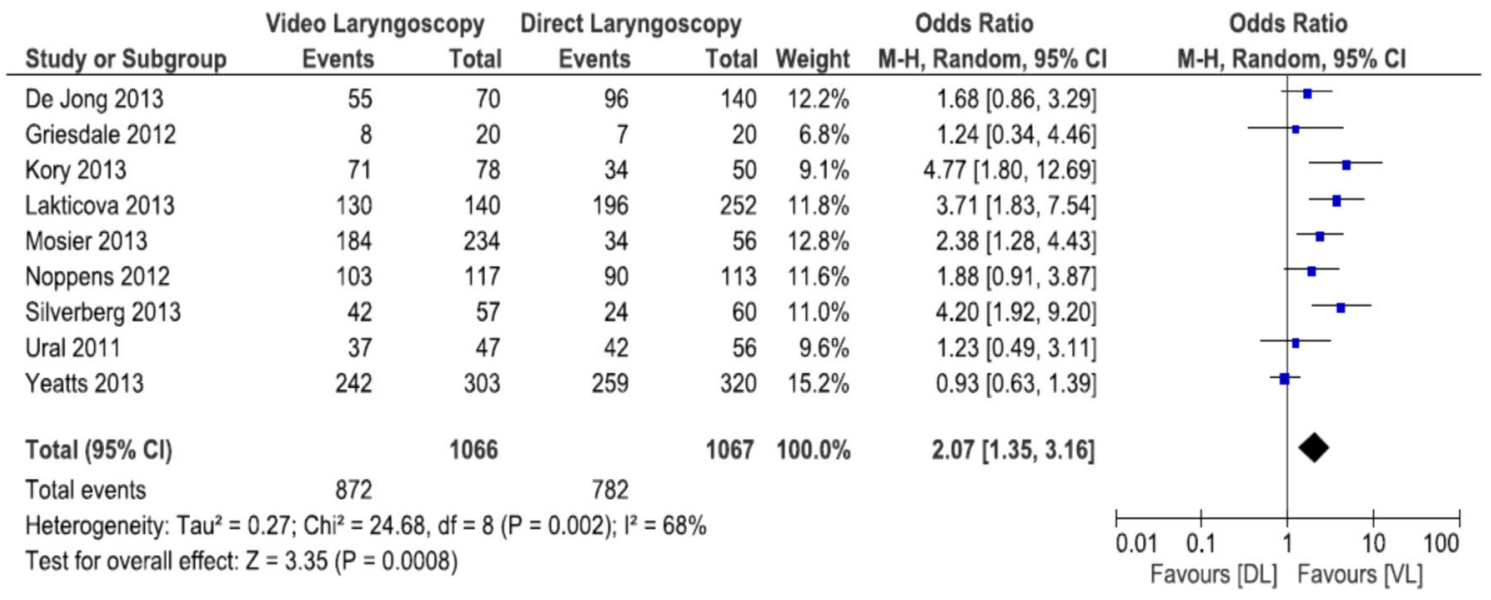

$\mathrm{M}-\mathrm{H}=$ Mantel-Haenszel

Fig. 3 Forest plot of first-attempt success

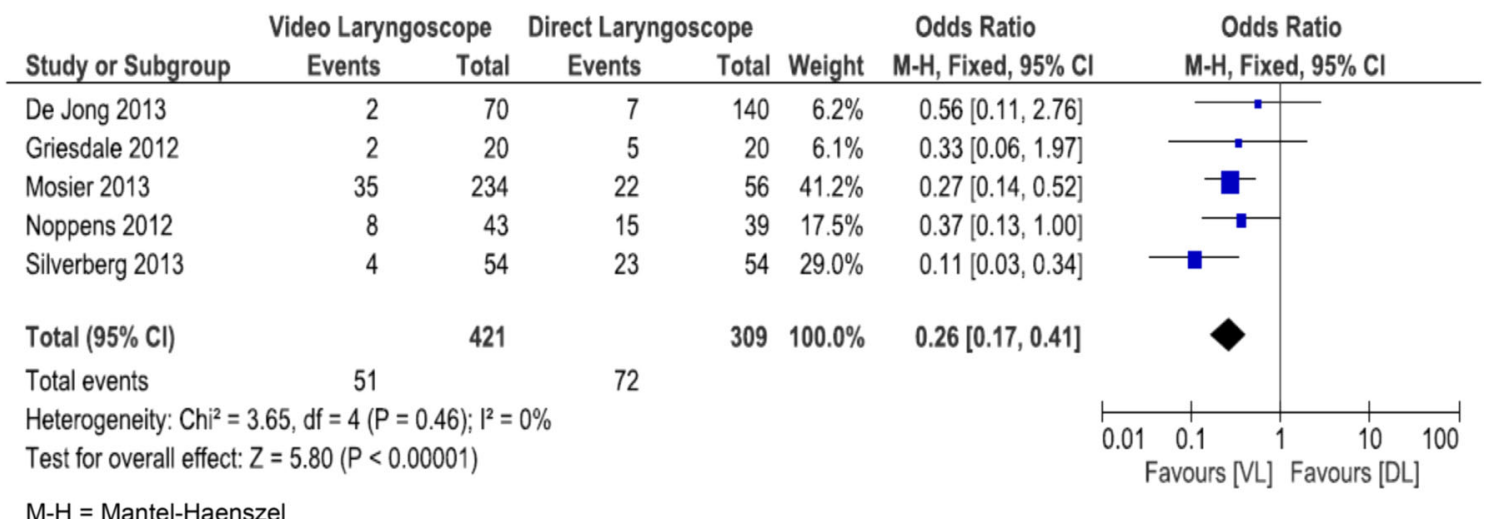

Fig. 4 Forest plot of glottis view 


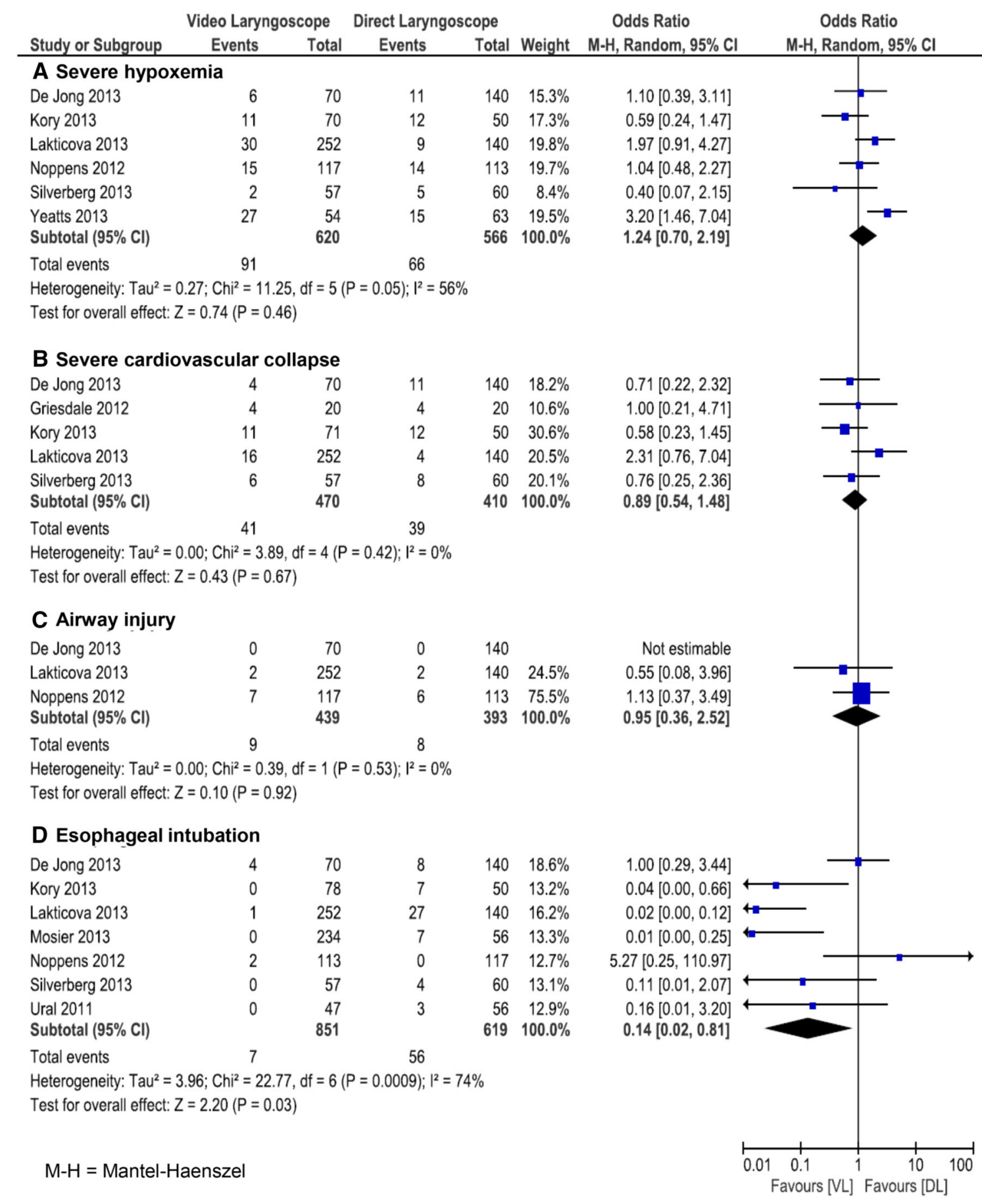

Fig. 5 Forest plot of complications related to intubation

\section{Severe cardiovascular collapse Airway injury}

Five studies presented results for the "severe cardiovascular Only three studies recorded airway injuries, with no airway collapse" outcome $[7,8,16,17,20]$. The pooled OR across injury in one of them $[8,18,20]$. The pooled OR across the the two studies was 0.93 (95\% CI 0.57-1.51, $p=0.77$, two studies was 0.96 (95\% CI 0.36-2.53, $p=0.93$, Fig. 5b), indicating no difference using VL when compared Fig. 5c), indicating no difference using VL when compared to DL. There was no heterogeneity for this outcome. to DL. There was no heterogeneity for this outcome. 


\section{Esophageal intubation}

Seven studies presented results for the "esophageal intubation" outcome [7, 8, 17-21]. The pooled OR across all studies was 0.14 (95\% CI 0.02-0.81, $p=0.03$, Fig. 5d), indicating less esophageal intubation using $\mathrm{VL}$ when compared to DL. There was significant between-study heterogeneity for this outcome $(Q=22.77, d f=6$, $p=0.0009)$, with a corresponding $I^{2}$ statistic of $74 \%$.

\section{Sensitivity analyses}

First, a sensitivity analysis including only Glidescope ${ }^{\circledR}$ studies was performed (Figs. E4-E7 in ESM). The results for all outcomes were similar to the results with all studies. The heterogeneity for esophageal intubation disappeared.

Second, a sensitivity analysis including only RCTs studies was performed (Figs. E8-E10 in ESM). The outcome "complications" was not analyzed because too few studies were available (one or two according to the complication). The results were significantly in favor of VL only for glottis view.

Third, a sensitivity analysis excluding the study with high risk of bias [21] was performed (Figs. E11-E13 in ESM). Again, the outcome "complications" was not analyzed because this study reported only esophageal intubation. The results for difficult intubation, firstattempt success, and glottis view were similar to the results including all studies.

Fourth, a sensitivity analysis excluding the trauma study [10] was performed (Figs. E14, E15 in ESM). Heterogeneity for first-attempt success and severe hypoxemia disappeared when excluding this study. The results for first-attempt success and complications were similar to the results including all studies.

\section{Discussion}

This systematic review and meta-analysis provides evidence that VL could be useful in airway management of ICU patients. Among the seven evaluated outcomes of interest, in comparison to DL, VL improved four of them (difficult OTI, first-attempt success, Cormack 3/4 grades, esophageal intubation) and did not modify three of them (severe hypoxemia, severe cardiovascular collapse, airway injury). To our knowledge, this is the first systematic review and meta-analysis of the effect of VL on ICU intubated patients.

Our systematic review and meta-analysis focused on the critical care setting, excluding emergency and anesthesia settings. In the emergency setting, several studies revealed similar results to our study. In one study by Sakles et al. C-MAC ${ }^{\circledR}$ was associated with a greater proportion of successful intubations and a greater proportion of Cormack-Lehane grade I or II views compared with a direct laryngoscope [22]. In other study by Sakles et al. Glidescope ${ }^{\circledR}$ had a higher overall success rate, and lower number of esophageal complications [23]. In cases of predicted difficult airway, Glidescope ${ }^{\circledR}$ had a higher success rate at first attempt than DL [24] and VL was associated with a higher first-pass success than DL [25]. In anesthesia settings, a recent meta-analysis [6] revealed that Glidescope ${ }^{\circledR}$ was associated with improved glottis visualization. To date, we found nine studies in the ICU; however, in anesthesia more than 50 studies are available.

In our study, glottis view was improved, which is concordant with the increase in first-attempt success and the decreases in difficult OTI and esophageal intubation. These results are comparable to those observed in operative rooms [6], except for first-attempt success. Indeed, first-attempt success with DL is already very high in operative rooms (more than $90 \%$ ) [26] and much higher than in the ICU $(60-91 \%)[1,4,27]$.

However, in the current study, severe complications related to intubation were not decreased by the VL, whether severe cardiovascular collapse or severe hypoxemia. The same result was observed for airway injury. We recently showed that difficult intubation was associated with complications related to intubation [1]; therefore, the decrease of difficult OTI incidence by the VL use should be associated with a decrease of complications. Furthermore, several authors have shown that the risk of complications increases with successive attempts. Consequently, the higher first-attempt success in the VL group should be associated with lower complications [2830]. This discordant result could be explained by a lack of power; indeed complications were not reported in all the studies included in the meta-analysis. In addition, several confounding factors such as sedation [31], pain [32], agitation [33], preoxygenation [34], recruitment maneuvers [35], or drugs used for intubation [36-40] could be associated with complications related to intubation in ICU, and were not assessed in these studies, particularly in observational studies, which have a higher risk of confounding factors. Finally, the method of laryngoscopy is only one potential factor in improving the intubation success and reducing the risk of severe complications. Training and education in (difficult) airway management is essential in order to improve patient safety at endotracheal intubation in the ICU.

We chose not to include time to intubate as an outcome because it was reported in only four studies [7, 10, $16,17]$, with various definitions and with very heterogeneous results.

One study [10] differed from the others, mostly because it was performed in trauma patients, a particular 
population of ICU patients, with an even higher risk of difficult intubation because of facial trauma, for example. Furthermore, the nature and level of operator experience were very eclectic in this study. However, the sensitivity analysis excluding this study did not show any differences from the global results.

The results of the study, however, should be viewed with caution for various reasons. First, studies were performed in several countries and in different ICU populations, including medical, surgical, and trauma patients, with widely differing mortality rates, from 7.5 to $41 \%$ in those that reported mortality, and with different operators with varying levels of experience. However, the same operators performed intubations with VL and DL. Second, VL devices differed across the studies: Glidescope $^{\circledR}, \mathrm{C}-\mathrm{Mac}^{\circledR}$, and McGrath Mac ${ }^{\circledR}$. The number of studies using C-Mac ${ }^{\circledR}$ or McGrath Mac ${ }^{\circledR}$ was too small to perform a subgroup analysis according to the device used. However, when considering only studies performed with Glidescope $^{\circledR}$, statistical heterogeneity for esophageal intubation disappeared. Third, most of the studies cited did not report in what way a failed intubation attempt was managed, whether guidelines for failed intubation were used, how long an intubation attempt was allowed before starting manual ventilation via mask or laryngeal mask, when to change the laryngoscopic approach or how the patient was prepared before intubation. Fourth, one study had a high risk of bias [21], which could affect conclusions of the meta-analysis. However, a sensitivity analysis excluding the study with high risk of bias did not reveal any significant changes on outcome. Fifth, only three included studies were RCTs. When performing a sensitivity analysis including only RCTs, there was a significantly better glottis view, but only a trend for more first-attempt success and less difficult intubation, without reaching significance. However, only three or two studies were included for each outcome, leading to a lack of power which was probably reached by adding observational studies. Finally, we did not include exclusively RCTs, which leads to an increased risk of bias. However, although some studies may not show VL to be better than DL, no study has shown DL to be superior, whether done in the simulator lab, operative room, emergency department, or ICU, and regardless of training or skill level of the operator. VL has always been shown to be at least as good as DL and most of the time better than DL.

In conclusion, this systematic review and meta-analysis provides evidence that VL for OTI in ICU helps to reduce difficult OTI, esophageal intubation, Cormack 3/4 grades, and increases first-attempt success, but does not reduce severe hypoxemia, severe cardiovascular collapse, or airway injury. Further large randomized studies are needed to determine if video laryngoscopes are able to reduce complications related to intubation.

Conflicts of interest The authors declare that they have no conflicts of interest related to the subject of the study.

\section{References}

1. De Jong A, Molinari N, Terzi N, Mongardon N, Arnal J-M, Guitton C, Allaouchiche B, Paugam-Burtz C, Constantin J-M, Lefrant J-Y, Leone M, Papazian L, Asehnoune K, Maziers N, Azoulay E, Pradel G, Jung B, Jaber S (2013) Early identification of patients at risk for difficult intubation in ICU: development and validation of the MACOCHA score in a multicenter cohort study. Am J Respir Crit Care Med 187:832-839. doi: 10.1164/rccm.201210-1851OC

2. Jaber S, Amraoui J, Lefrant J-Y, Arich C, Cohendy R, Landreau L, Calvet Y, Capdevila X, Mahamat A, Eledjam J-J (2006) Clinical practice and risk factors for immediate complications of endotracheal intubation in the intensive care unit: a prospective, multiple-center study. Crit Care Med 34:2355-2361. doi:10.1097/01.ccm.0000233879. 58720.87
3. Jaber S, Jung B, Corne P, Sebbane M, Muller L, Chanques G, Verzilli D, Jonquet O, Eledjam J-J, Lefrant J-Y (2010) An intervention to decrease complications related to endotracheal intubation in the intensive care unit: a prospective, multiple-center study. Intensive Care Med 36:248-255. doi: 10.1007/s00134-009-1717-8

4. Griesdale DEG, Bosma TL, Kurth T, Isac G, Chittock DR (2008)

Complications of endotracheal intubation in the critically ill. Intensive Care Med 34:1835-1842. doi: 10.1007/s00134-008-1205-6

5. Szmuk P, Ezri T, Evron S, Roth Y, Katz J (2008) A brief history of tracheostomy and tracheal intubation, from the Bronze Age to the Space Age. Intensive Care Med 34:222-228. doi: 10.1007/s00134-007-0931-5
6. Griesdale DEG, Liu D, McKinney J, Choi PT (2012) Glidescope ${ }^{\circledR}$ videolaryngoscopy versus direct laryngoscopy for endotracheal intubation: a systematic review and meta-analysis. Can J Anaesth 59:41-52. doi:10.1007/s12630-011-9620-5

7. Kory P, Guevarra K, Mathew JP, Hegde A, Mayo PH (2013) The impact of video laryngoscopy use during urgent endotracheal intubation in the critically ill. Anesth Analg 117:144-149. doi: 10.1213/ANE.0b013e3182917f2a

8. De Jong A, Clavieras N, Conseil M, Coisel Y, Moury PH, Pouzeratte Y, Cisse M, Belafia F, Jung B, Chanques G, Molinari N, Jaber S (2013) Implementation of a combo videolaryngoscope for intubation in critically ill patients: a before-after comparative study. Intensive Care Med 39:2144-2152. doi:

10.1007/s00134-013-3099-1 
9. Larsson A, Dhonneur G (2013)

Videolaryngoscopy: towards a new standard method for tracheal intubation in the ICU? Intensive Care Med 39:2220-2222. doi: 10.1007/s00134-013-3118-2

10. Yeatts DJ, Dutton RP, Hu PF, Chang YW, Brown CH, Chen H, Grissom TE, Kufera JA, Scalea TM (2013) Effect of video laryngoscopy on trauma patient survival: a randomized controlled trial. J Trauma Acute Care Surg 75:212-219. doi:10.1097/TA.0b013e318293103d

11. Liberati A, Altman DG, Tetzlaff J, Mulrow C, Gotzsche PC, Ioannidis JP, Clarke M, Devereaux PJ, Kleijnen J, Moher D (2009) The PRISMA statement for reporting systematic reviews and meta-analyses of studies that evaluate healthcare interventions: explanation and elaboration. BMJ 339:b2700

12. Apfelbaum JL, Hagberg CA, Caplan RA, Blitt CD, Connis RT, Nickinovich DG, Benumof JL, Berry FA, Bode RH, Cheney FW, Guidry OF, Ovassapian A (2013) Practice guidelines for management of the difficult airway: an updated report by the American Society of Anesthesiologists Task Force on Management of the Difficult Airway. Anesthesiology 118:251-270. doi: 10.1097/ALN.0b013e31827773b2

13. Higgins JPT GS (2011) Cochrane handbook for systematic reviews of interventions version 5.1.0. The Cochrane Collaboration. http://www.cochrane-handbook.org. Accessed 1Oct 2013

14. Wells GA SB, O'Connell D, Peterson J, Welch V, Losos M (2009) The Newcastle-Ottawa Scale (NOS) for assessing the quality of nonrandomized studies in metaanalyses.

http://www.ohri.ca/programs/ clinical_epidemiology/oxford.asp. Accessed 25 Jul 2012

15. Mesgarpour B, Heidinger BH, Schwameis M, Kienbacher C, Walsh C, Schmitz S, Herkner H (2013) Safety of off-label erythropoiesis stimulating agents in critically ill patients: a metaanalysis. Intensive Care Med 39:1896-1908 doi: 10.1007/s00134-013-3030-9

16. Griesdale DE, Chau A, Isac G, Ayas N, Foster D, Irwin C, Choi P (2012) Video-laryngoscopy versus direct laryngoscopy in critically ill patients: a pilot randomized trial. Can J Anaesth 59:1032-1039. doi: $10.1007 / \mathrm{s} 12630-012-9775-8$

17. Silverberg M, Li N, Kory P (2013) Efficacy of video laryngoscopy vs. direct laryngoscopy during urgent endotracheal intubation: a randomized controlled trial. Chest J 144: 580A580A. doi: $10.1378 /$ chest. 1689305
18. Noppens RR, Geimer S, Eisel N, David M, Piepho T (2012) Endotracheal intubation using the $\mathrm{C}$-MAC $(\mathrm{R})$ video laryngoscope or the Macintosh laryngoscope: a prospective, comparative study in the ICU. Crit Care 16:R103. doi:10.1186/cc1138

19. Ural K, Subaiya C, Taylor C, Ramadhyani U, Scuderi-Porter H, Nossaman BD (2011) Analysis of orotracheal intubation techniques in the intensive care unit. Crit Care Resusc 13:89-96

20. Lakticova V, Koenig SJ, Narasimhan M, Mayo PH (2013) Video laryngoscopy is associated with increased first pass success and decreased rate of esophageal intubations during urgent endotracheal intubation in a medical intensive care unit when compared to direct laryngoscopy. J Intensive Care Med. doi:10.1177/0885066613492641

21. Mosier JM, Whitmore SP, Bloom JW, Snyder LS, Graham LA, Carr GE, Sakles JC (2013) Video laryngoscopy improves intubation success and reduces esophageal intubations compared to direct laryngoscopy in the medical intensive care unit. Crit Care 17:R237. doi:10.1186/cc13061

22. Sakles JC, Mosier J, Chiu S, Cosentino M, Kalin L (2012) A comparison of the $\mathrm{C}$-MAC video laryngoscope to the Macintosh direct laryngoscope for intubation in the emergency department. Ann Emerg Med 60:739-748. doi: 10.1016/j.annemergmed.2012.03.031

23. Sakles JC, Mosier JM, Chiu S, Keim SM (2012) Tracheal intubation in the emergency department: a comparison of GlideScope(R) video laryngoscopy to direct laryngoscopy in 822 intubations. J Emerg Med 42:400-405. doi: S0736-4679(11)00529-4

24. Mosier JM, Stolz U, Chiu S, Sakles JC (2012) Difficult airway management in the emergency department: GlideScope videolaryngoscopy compared to direct laryngoscopy. J Emerg Med 42:629-634. doi: S0736-4679(11)00627-5

25. Sakles JC, Patanwala AE, Mosier JM, Dicken JM (2013) Comparison of video laryngoscopy to direct laryngoscopy for intubation of patients with difficult airway characteristics in the emergency department. Intern Emerg Med. doi: 10.1007/s11739-013-0995-x

26. Langeron $\mathrm{O}$, Cuvillon $\mathrm{P}$, Ibanez-Esteve C, Lenfant F, Riou B, Le Manach Y (2012) Prediction of difficult tracheal intubation: time for a paradigm change Anesthesiology 117:1223-1233. doi: 10.1097/ALN.0b013e31827537cb
27. Simpson GD, Ross MJ, McKeown DW, Ray DC (2012) Tracheal intubation in the critically ill: a multi-centre national study of practice and complications. $\mathrm{Br}$ J Anaesth 108:792-799. doi: 10.1093/bja/aer504

28. Cook TM, Woodall N, Harper J, Benger J (2011) Major complications of airway management in the UK: results of the Fourth National Audit Project of the Royal College of Anaesthetists and the Difficult Airway Society. Part 2: intensive care and emergency departments. Br J Anaesth 106:632-642. doi:10.1093/bja/aer059

29. Mort TC (2004) Emergency tracheal intubation: complications associated with repeated laryngoscopic attempts. Anesth Analg 99:607-613, table of contents. doi: 10.1213/01.ane.0000122825.04923.15

30. Sakles JC, Laurin EG, Rantapaa AA, Panacek EA (1998) Airway management in the emergency department: a one-year study of 610 tracheal intubations. Ann Emerg Med 31:325-332

31. Chanques G, Jaber S (2007) Sedation assessment tool, sedation-algorithm, choice of sedation drugs: intricate concepts of an emergent clinical practice. Intensive Care Med 33:554-555

32. Chanques G, Payen JF, Mercier G, de Lattre S, Viel E, Jung B, Cisse M, Lefrant JY, Jaber S (2009) Assessing pain in non-intubated critically ill patients unable to self report: an adaptation of the Behavioral Pain Scale. Intensive Care Med 35:2060-2067. doi: 10.1007/s00134-009-1590-5

33. Chanques G, Jaber S, Barbotte E, Violet S, Sebbane M, Perrigault PF, Mann C, Lefrant JY, Eledjam JJ (2006) Impact of systematic evaluation of pain and agitation in an intensive care unit. Crit Care Med 34:1691-1699

34. Baillard C, Fosse JP, Sebbane M, Chanques G, Vincent F, Courouble P, Cohen Y, Eledjam JJ, Adnet F, Jaber S (2006) Noninvasive ventilation improves preoxygenation before intubation of hypoxic patients. Am J Respir Crit Care Med 174:171-177

35. Constantin JM, Futier E, Cherprenet AL, Chanques G, Guerin R, CayotConstantin S, Jabaudon M, Perbet S, Chartier C, Jung B, Guelon D, Jaber S, Bazin JE (2010) A recruitment maneuver increases oxygenation after intubation of hypoxemic intensive care unit patients: a randomized controlled study. Crit Care 14:R76. doi:10.1186/cc8989 
36. Hedenstierna G, Edmark L (2005) The effects of anesthesia and muscle paralysis on the respiratory system. Intensive Care Med 31:1327-1335. doi: 10.1007/s00134-005-2761-7

37. Vinclair M, Broux C, Faure P, Brun J, Genty C, Jacquot C, Chabre O, Payen JF (2008) Duration of adrenal inhibition following a single dose of etomidate in critically ill patients. Intensive Care Med 34:714-719. doi:

10.1007/s00134-007-0970-y
38. Albert SG, Ariyan S, Rather A (2011) The effect of etomidate on adrenal function in critical illness: a systematic review. Intensive Care Med 37:901-910. doi: 10.1007/s00134-011-2160-1

39. Asehnoune K, Mahe PJ, Seguin P, Jaber S, Jung B, Guitton C, Chatel-Josse N, Subileau A, Tellier AC, Masson F, Renard B, Malledant Y, Lejus C, Volteau C, Sebille V, Roquilly A (2012) Etomidate increases susceptibility to pneumonia in trauma patients. Intensive Care Med 38:1673-1682. doi:10.1007/ s00134-012-2619-8
40. Jung B, Clavieras N, Nougaret $\mathrm{S}$, Molinari N, Roquilly A, Cisse M, Carr J, Chanques G, Asehnoune K, Jaber S (2012) Effects of etomidate on complications related to intubation and on mortality in septic shock patients treated with hydrocortisone: a propensity score analysis. Crit Care 16:R224. doi:10.1186/cc11871 